\title{
When Strangers Start to Gossip: Investigating the Effect of Gossip on Cooperation in a Prisoner's Dilemma Game
}

\author{
Charlotte J. S. De Backer ${ }^{1}$ Christina Larson ${ }^{2}$ - Maryanne L. Fisher ${ }^{3}$. \\ Francis T. McAndrew ${ }^{4} \cdot$ Konrad Rudnicki $^{1}$
}

Published online: 11 July 2016

(C) Springer International Publishing 2016

\begin{abstract}
Previous research indicates gossip is a social bonding system that is use to establish shared acquaintances and/ or attitudes, to punish group norm violators, or for coercion via invoking fear of gossipmongers. However, no empirical work explores directly the relationship between gossip about freeloaders leading to improved cooperation in recipients. Thus, we predicted that the sharing of negative gossip about the freeloading behavior of a third party will lead to higher levels of cooperation. Using levels of cooperation in a prisoner's dilemma game as a proxy to measure social bonding, we compared cooperation levels of 60 female respondents who met with a confederate randomly assigned to one of three conditions. They either (1) did not talk or were exposed to (2) negative reputation gossip or (3) self-disclosed negative reputation information. Results show that, even after controlling for a list of potential confounding factors, cooperation levels are high in both the control and self-disclosure condition and are significantly lower in the gossip condition. We suggest that gossip may spark initial relations, yet is insufficient to ignite a social bond sustained by cooperative action among complete strangers.
\end{abstract}

Charlotte J. S. De Backer

charlotte.debacker@uantwerpen.be

1 Department of Communication Sciences, University of Antwerp, Sint-Jacobstraat 2, 2000 Antwerp, Belgium

2 Department of Psychology, University of California Los Angeles, Los Angeles, CA, USA

3 Department of Psychology, Saint Mary's University, Halifax, NS, Canada

4 Department of Psychology, Knox College, Galesburg, IL, USA
Keywords Gossip · Cooperation · Prosocial behavior · Reputation $\cdot$ Social dilemma games

Listed as a human universal (Brown 2004), gossip is of all times and cultures. It has been argued that language emerged and evolved in the form of gossip, as it helped to solve adaptive functions of group living. These functions include the need for a mechanism to sustain group cohesion and identify threats of free-riders invading the group (see Dunbar 1993). Gossip serves multiple functions including entertainment, cultural learning, sharing information, social bonding, and altering reputations (see Foster 2004 and Beersma and Van Kleef 2012 for an overview). Generally, people often not show much respect for gossip, instead seeing it as a form of aggression or teasing (Baumeister, Zhang and Vohs, 2004). Yet, while gossip can be - and is - used as a manipulative tool to ruin the reputations of others (e.g., Paine 1967; McAndrew and Milenkovic 2002), the sharing of even negative information about third parties may have positive outcomes for those who share the gossip. For example, "by describing the unacceptable actions of a non-group member towards a group member, this gossip activity creates cohesiveness and reaffirms friendships within a group" (Saunders 1999, p. 287).

The idea that gossip is a social bonding system originates from James West (1945) who first made the connection between gossip and the maintenance of group unity. In the 1990s, Robin Dunbar (1993, 1996, 2004) framed this use of gossip in a clear and evidence-based evolutionary framework. Correlations between the evolution of the neocortical size, group size, and language in humans illustrate how language, and gossip in particular, enabled our ancestors to acquire valuable reputation information about others at a higher speed than learning by personal interactions and observations alone. Individuals who wanted to interact with each other did not 
need to rely on personal experiences to know who could be trusted or not, but simply had to attune to gossip. This use of gossip, exchanging reputation information, enabled our ancestors to start living in larger social settings (Panchanathan and Boyd 2003). Like other animals, humans via gossip use alarm calls to warn others about freeloaders. These warning calls may well be seen as a form of prosocial behavior. Moreover, it has been shown that especially people with more prosocial orientations engage in this type of gossip (Feinberg et al. 2012b), which is appreciated by those who receive the information. Indeed, Wilson et al. (2000) showed that people rate the behavior of a gossiper sharing the norm violations of a third party positively, while not sharing the information about the misbehavior of freeloaders, as inappropriate.

The proximate reasons for why gossip connects people are twofold, according to Gluckman $(1963,1968)$. First of all, he says, gossip marks social groups. Gossip is a tool to make clear who is part and who is not part of a group. Outsiders simply cannot understand the gossip of a group sharing a social history and culture (Liang 1993; Riegel 1996). Not surprisingly, gossip is also often associated with themes of us vs. them (Gelles 1989). The sharing of negative attitudes towards mutually known third parties especially seems to contribute to this group delineation and may even elicit feelings of closeness among strangers (Bosson et al. 2006; Weaver and Bosson 2011). Second, Gluckman $(1963,1968)$ says that gossip is used to communicate about group norms and scandalize those who violate these norms. In this perspective, gossip unites because it enforces conformity of group members. Researchers have extensively reported on the use of gossip as a tool to identify and punish norm violators, who take advantage of others without reciprocating in any sense (e.g., Arno 1980; Cox 1970; Eder and Enke 1991; Gelles 1989; Gluckman 1963; Hannerz 1967; Kuttler et al. 2002; Levin and Kimmel 1977; Merry 1984; Morreall 1994; Percival 2000; Post 1994; Rosnow 1977; Saunders 1999; Schoeman 1994; Smith et al. 1999; Thomas 1994; Wilson et al. 2000; Young 2001). It has been shown that it is the negative arousal elicited by freeloading behavior that drives gossipers to share the information and punish their target (Baxter, Dun and Sahlstein 2012; Feinberg et al. 2012a). The consequences of this type of gossip can be considerable. For instance, acquiring reputation information via gossip leads to similar changes in behavior towards the target, compared to when people acquired the information by personal direct observation (Sommerfeld et al. 2007). More specifically, when acquiring via gossip that one is not to be trusted to cooperate with, this person is less likely to be selected as a cooperation partner in future interactions with others (Feinberg et al. 2014).

With gossip outlining group boundaries and norms, and punishing those who violate these norms, gossip thus establishes and reinforces social cohesion (Gluckman 1963, 1968). It sets the context for a system where gossip enforces cooperation by punishing those who do not cooperate. Interestingly, the mere threat of being gossiped about seems to be sufficient to boost cooperation in social dilemma games (Beersma and Van Kleef 2011; Piazza and Bering 2008). Kurland and Pelled (2000) also referred to this pattern in their theoretical model about gossip and power. They predicted that especially negative gossip would lead to coercive power. That is, those who hear negative gossip will fear the gossiper sharing this information, because they are afraid of becoming a target of negative gossip themselves.

Previous studies investigating gossip in the context of social dilemma games (e.g., Beersma and Van Kleef 2011; Feinberg et al. 2012a; Feinberg et al. 2014; Piazza and Bering 2008) have always focused on the dynamics between the participants of these social dilemma games. In contrast, theories such as those of Kurland and Pelled (2000), Gluckman $(1963,1968)$ and Dunbar $(1993,1996,2004)$ appear to predict a broader effect of gossip. In summary of what we have outlined above, these theories suggest that any gossip about the misconduct of a third party will establish social cohesion between gossipers because the gossip information sets the (good) gossipers apart from the (bad) target, punishes the target, and emphasizes social norms, while posing a threat not to behave badly or else one will be gossiped about. Based on this evidence, it can be predicted that the sharing of negative gossip about the freeloading behavior of any third party will lead to higher levels of social cohesion and cooperation. Here, we test this prediction.

\section{Methodology}

\section{Study Design}

We used a prisoner's dilemma game (PDG), where the best strategy for all players is to defect (behave selfishly), but collectively, the best outcome is for everyone to cooperate. We applied the parameterization of a PDG as depicted in Fig. 1. The PDG was preferable to other economic games for the purpose of our study for several reasons. First of all, the PDG is symmetric. Respondents are not assigned to different roles, as is the case in games such as the ultimatum game and the dictator game, where the role of a presenter is preferable to that of a responder. Second, unlike other games, the PDG only has one Nash equilibrium, which allows us to purely test differences in cooperation only, ignoring other issues of coordination (Ortmann and Tichy 1999). In the PDG, the defective strategy - when both players choose not to cooperate - is the unique Nash equilibrium, while the cooperative strategywhen both players choose to cooperate-implements the Pareto-optimal outcome. Linking these to the above outlined theory on gossip, the cooperative strategy corresponds to 


\begin{tabular}{l|ll} 
& PLA YER 2 & \\
PLAYER 1 & Chooses to & Chooses to NoT \\
COOPERATE & COOPERATE \\
Chooses to COOPERATE & Player 1 gets \$3 & Player 1 loses \$1 \\
& Player 2 gets \$3 & Player 2 gets \$5 \\
\hline Chooses to NOT & Player 1 gets \$5 & Player 1 gets nothing \\
COOPERATE & Player 2 loses \$1 & Player 2 gets nothing \\
& &
\end{tabular}

Fig. 1 Pay-off schedules used in the experiment

reciprocation and social bonding, while the defective strategy corresponds to free-riding and non-unity.

Our research design consisted of three empirical conditions. The conditions were (1) a control condition where no verbal communication preceded the games, (2) a selfdisclosure condition (described in detail below), and (3) a gossip condition. In the gossip condition, the confederate told the following story to all participants:

"Oh my god, I know that experimenter! I saw her last week in our parking lot. I was sitting at my desk at our bedroom window, and she was just leaving the parking lot. She hit another car when she was driving out the parking spot, and she sure noticed, because it was quite a hard smash, but she just looked around, did not notice me or anyone else and she drove off! She did not even get out of her car to see how bad the other car was damaged, or leave a message or anything. I thought it was just so mean of her!"

The gossip story consisted of an act of norm violation, as the society where this study was conducted considers bumping into a car leaving a dent and driving off without leaving a note containing one's contact information to be a case of inappropriate hit-and-run.

In the next condition, the same scenario was used, but this time the confederate self-disclosed the hit-and-run story. It is well-known that allowing communication prior to playing social dilemma games can increase levels of cooperation (for an overview, see Sally 1995). To control for the potential effect of "mere talking" prior to playing the game, we added a selfdisclose condition as an extra control condition. In this condition, the confederate tells the exact same story as in the gossip condition, but this time about herself:
"Oh my god, I made it in time. I was in such a hurry to get here. I left home way too late, and I even hit a car when I was leaving our parking lot. It was quite a smash, but no one was around to see it, so I just drove off. I did not want to lose any more time to get out and check the damage. Cause you know, these things happen. I don't think it's the end of the world, and I would not have wanted to miss the opportunity to earn some extra money here!"

When talking about herself, the confederate did not use gossip about a third party to mark a difference between the gossipers and the target and did not signal any threats of potentially sharing gossip about her conversation partner in the future. It can therefore be expected that when the confederate shared the hit-and-run story about herself, this communication will not affect the cooperation levels of the receivers of such information. However, since the self-disclosed information concerns the sharing of personal norm violation, it can be assumed that the self-disclosure condition may even lower the tendency to cooperate among receivers.

In the control condition, both players met with each other prior to playing the game, but could not communicate verbally. Bohnet and Frey (1999) found that when participants merely stood and identified the members of their group, they behaved more cooperatively than when group members were anonymous. Thus, if the results from the two other conditions are different from our control condition, the effect is due to the verbal interaction and not to other factors involved with meeting face to face.

For all conditions, one of the players was a confederate. Two professional actresses were hired for the roles of the confederates in the experiment. One of the confederates was a 22-year-old student enrolled in the University of California, Los Angeles School of Theater, Film, and Television. The other was an 18-year-old student of Santa Barbara High School, who had been active in the school's Theatre for several years and participated in an acting summer camp at the New York Film Academy. Except for the control condition, the confederates took the role of sharing information, placing the actual respondents in the role of receivers. This study received Humans Subjects Approval from the University of California, Santa Barbara.

\section{Sample}

All 60 respondents were female students recruited on the campus of the University California, Santa Barbara. Their ages ranged from 18 to 28 , with an average of $M_{\text {age }}=20.62$ $(S D=2.05$, Median $=20, N=55,5 \mathrm{did}$ not report their age $)$. These ages were not significantly different between the three research conditions or in between the groups with the different actresses. 
The effects of sex on cooperation in social dilemma games are complicated, but there is no doubt that it is an important explanatory variable that must be taken into account (Ortmann and Tichy 1999). A meta-analysis of sex differences in cooperation showed that both men and women's levels of cooperation are different in mixed dyads vs. same-sex dyads and, while it is often assumed that women are more cooperative, female-female interactions seem less cooperative than malemale interactions (Balliet et al. 2011). Thus, due to sex differences that occur in social dilemma games, we limited this study to a same-sex female-female interaction design. Moreover, this decision was also based on the evidence that shows sex differences in bonding behaviors and the associated role of gossip. When forming bonds, men and women put emphasis on different types of content for different reasons. More than women, men focus on the informational aspect of gossip, which improves their access to resources and status (Watson 2012). More than men, women use gossip to make social comparisons, establish solidarity, and strengthen ingroup cohesion (Hess and Hagen 2006a, b; Leaper and Holliday 1995; Levin and Arluke 1985; Nevo and Nevo 1993; Nevo et al. 1994) because they pursue mostly trust and intimacy, which secures the presence of emotional support (Hall 2011). Due to this variation in values that guide bonding, gossip as a tool for bond creation is used for different purposes by both sexes. Additionally, studies have consistently shown that women gossip more than men do, especially in situations relevant to cooperation and conflict (McAndrew 2014). In this study, gossip is linked to cooperation, and due to all of the stated reasons, it is likely that gossip may influence cooperation differently in men and women, and consequently, it is sensible to examine its effect at a within-sex level.

\section{Procedure}

All participants were tested in a laboratory room that led to a small office. Two participants came to the laboratory at a set time. These two participants were greeted by a female experimenter and then paired up with one of the two confederates. Both the participants and the confederates received $\$ 5$ for showing up and were told they would be playing some games, followed by completing a brief questionnaire. After this brief introduction, the experimenter excused herself and asked the participants to wait for a minute while she gathered the materials to play the game. In the control condition, before leaving the room, the experimenter asked the participants not to speak while she was gone. A second experimenter used a monitor in the office linked to a hidden camera in the laboratory to observe what transpired, and we can confirm that no communication took place for any of the control participants. In the gossip condition and the self-disclosure condition, the confederate would disclose the information (presented in the "Study
Design" section) to the participant while the experimenter was absent.

Upon return, the experimenter explained to the participants the rules of the game and informed them that they would be playing several rounds, although the exact number was not mentioned. The respondents were instructed to choose between cooperating and not cooperating with the other player, in each round of the game. Participants were told that they could not communicate with the other player and would have to play each round without knowing the decisions of the other player in the previous rounds. They were also told that they would receive a payment dependent on the choices both of them made during one randomly decided round of all rounds played and were given a handout of a pay-off matrix (see Fig. 1), in addition to the verbal instructions of the game. After the instructions and answers to any remaining questions, both the participant and the confederate were re-seated at opposite sides of the room, facing away from each other to ensure the anonymity of their responses and that non-verbal communication would not take place while playing the PDG. The confederate and participant then played five rounds of the game, using printed cards they put into envelopes.

After the games, all participants completed a survey to measure their perceptions of the other player. It included the questions: How friendly was the other player? How likeable was the other player? How much did you like the other player? How trustworthy was the other player? How honest was the other player? How intelligent was the other player? How cooperative was the other player? How much did you identify with the other player? All questions were measured on seven-point Likert-type scales, such that $1=$ not at all and $7=$ very much. On the last page of the survey, all participants, across conditions, were asked to rate the behavior of people involved in the scenarios used in both the gossip and self-disclosure condition. This step was to control whether participants rated the behavior of self-discloser and the gossip target as negative and the behavior of the gossiper as positive. Upon reading the gossip scenario, they were asked, "How would you rate the behavior of the subject of this scenario (the one talked about)?" and, "How would you rate the behavior of the person telling you this information?" They responded on a seven-point Likert-type scale, ranging from $1=$ very negative to $7=$ very positive. Upon reading the scenario from the self-disclosure condition, respondents were asked, using the same scale, "How would you rate the behavior of this person?"

After completing the survey, the participants each met separately with the experimenter in a separate room to be paid. They were then debriefed about the actual scope and design of the study. The confederates were asked to cooperate in every round; so all participants received either $\$ 3$ or $\$ 5$ for the games (in addition to the $\$ 5$ for showing up; see Fig. 1). 


\section{Results}

Manipulation check Results show that the behavior of the gossiped-about person (i.e., "the gossipee") and the behavior of the person who self discloses her bad behavior (i.e., "the self-discloser") are not significantly different, $t(59)=.56$, $p=.58$. Both were scored rather negatively: $M_{\text {gossip-sub- }}$ ject $=2.40(S D=0.98)$ and $M_{\text {self-disclosed }}=2.30(S D=1.37)$. The behavior of the one who shares the gossip is viewed significantly more positively $\left(M_{\text {gossiper }}=3.75, S D=1.07\right)$ than both the gossipee, $t(59)=7.18, p<.001$, and the self-discloser $t(59)=6.35, p<.001$.

\section{Effect of self-disclosure and gossip on level of cooperation}

We first looked at the total level of cooperation of each respondent. The average levels of cooperation over the five rounds of the PD game are $50 \%$ for the gossip condition and $69 \%$ for both the control and self-disclosure condition. A new variable was created for total cooperation rates, such that cooperating in no round yielded a score of 0 , cooperating in 1 round equaled a score of 1 , and so on, for a maximum score of 5 , for all 5 rounds. A betweensubject analysis of variance model (ANOVA) with this total cooperation score as dependent variable and condition (control vs. self-disclosure vs. gossip) as independent variable was used. This ANOVA confirmed that participants in the control and self-disclosure condition significantly cooperated more often $\left(M_{\text {control }}=3.20, S D=1.28, n=20\right.$ and $\left.M_{\text {self }}=3.45, S D=.89, n=20\right)$ than did the participants in the gossip condition $\left(M_{\text {gossip }}=2.50, S D=1.24, n=20\right), F$ $(2,58)=3.68, M S E=1.32, p<.05, \eta_{p}{ }^{2}=0.060$.

A multivariate analysis of variance (MANOVA) model was used to look at the results of each of the five rounds of the game that was played. Results show that the effect is significant for round $1, F(2,58)=5.41, M S E=.13, p<.01$, $\eta_{p}{ }^{2}=0.085 ;$ round $2, F(2,58)=4.05, M S E=.21, p<.05$, $\eta_{p}{ }^{2}=0.065 ;$ and round $4, F(2,58)=6.64, M S E=.20, p<.01$, $\eta_{p}{ }^{2}=0.103$, but not for round $3, F(2,58)=.19, M S E=.26$, $p=.83, \eta_{p}{ }^{2}=0.003$, nor round $5, F(2,58)=.78, M S E=.26$, $p=.46, \eta_{p}{ }^{2}=0.008$. Closer examination of each round (see Fig. 2) shows that in the first round, 18 of the 20 female participants in the control condition chose to cooperate $(90.0 \%)$, while in the self-disclosure condition, 19 players (95.0\%) opted for cooperation. In the gossip condition, the number of cooperators in the first was 12 participants $(60.0 \%)$. In the second round, all levels of cooperation dropped (70\% control; $80 \%$ self-disclosure; $40 \%$ gossip). In the third round, the levels of cooperation decreased further for the control $(60 \%)$ and self-disclosure conditions $(50 \%)$, but the level of cooperation increased (55\%) in the gossip condition. In the fourth round, the levels of cooperation in the control and self-disclosure conditions went up again (85\% control; $70 \%$ self-disclosure), while in the gossip condition, the level of cooperation dropped again (35\%). In the fifth and last round, the levels of cooperation dropped again in the control $(40 \%)$ and self-disclosure $(50 \%)$ conditions, while the level of cooperation in the gossip condition increased $(60 \%)$.

Controlling for actress To rule out the possible effect that a difference in acting between the two actresses might have influenced our results, we added the dummy coding for the actresses as a control variable to an ANOVA analysis with the total cooperation score as dependent variable and condition (control vs. self-disclosure vs. gossip) as independent variable. This model result revealed no significant effect of the actress condition and still lower levels of cooperation rates in the gossip condition than in the control or self-disclosure condition, $F(2,58)=3.63, M S E=1.34, p<.05, \eta_{p}{ }^{2}=0.058$.

Controlling for perceptions of confederate Comparing the mean scores on all items for the three experimental groups, a
Fig. 2 Percentage of cooperation in the five rounds of the PD game by condition

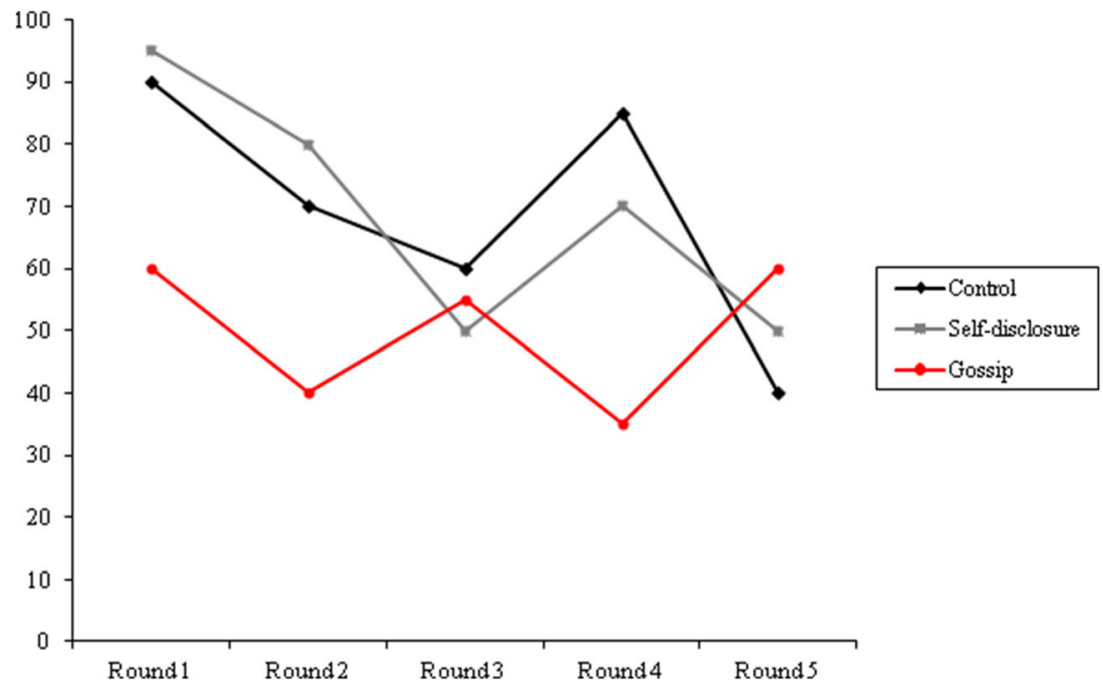


MANOVA analysis was used with all perception variables as dependents and the condition as independent (see Table 1 for all results). A significant $p<.05$ difference was found for perceived trustworthiness. Looking at the post hoc results of a least square difference test, the self-disclosed condition and the gossip condition are significantly different from each other, $p<.05$, yet both are not significantly different from the control condition. All other items were not significantly different at the $p<.05$ level across the experimental groups. However, a considerable trend towards significance, $p=.05$, was found for perceived friendliness, with the gossip confederate scoring highest (see Table 1).

Due to the low numbers in each cell $(n=20)$, separate analyses of covariance (ANCOVA) with condition as the independent variable and total level of cooperation as the dependent variable were run with each of these questions as a single covariate. The perceived friendliness of the confederate had no effect, nor did overall likeability, personal likeability, trustworthiness, intelligence, cooperativeness, or the participant's perceived identification with the confederate, yet for each of these, the condition remained significant (analyses excluded for brevity, available upon request). The perceived honesty of the confederate had no effect either, $F(1,59)=.73$, $M S E=1.34, p=.40, \eta_{p}{ }^{2}=0.012$, but the condition became non-significant, $F(2,58)=2.56, M S E=1.34, p=.09$, $\eta_{p}{ }^{2}=0.042$, when this item was added as a covariate. To further investigate this latter finding, we ran a regression analysis with perceived honesty as the independent variable and total cooperation as the dependent variable for the three conditions separately. No effect could be found in the gossip and the control condition, but in the self-disclosure condition the results show that participants were less cooperative when they perceived the confederate as dishonest $(t(1,19)=-2.42$, $\beta=-.50, p<.05$ ).

\section{Discussion}

Our study reveals some unexpected and somewhat ambivalence results. Firstly, participants who distrusted the confederate self-disclosing a hit-and-run situation were less likely to cooperate with this person. However, on average, this selfdisclosing condition was not significantly different from the control condition where participants did not talk to the confederate at all, and both were significantly different from the gossip condition. This signals, first of all, that although any talk prior to playing social dilemma games can increase levels of cooperation (see Sally 1995), there is something special about gossip that other talk may not display. We know from earlier studies on gossip in the context of social dilemma games (e.g., Beersma and Van Kleef 2011; Feinberg et al. 2011; Feinberg et al. 2014; Piazza and Bering 2008) that (potential) gossip about the participants of such games boosts cooperation. Our findings add to that literature by showing that even gossip about people who do not participate in social dilemma games may have an effect. However, our results are not in keeping with these earlier findings and not fully as we had anticipated, based on theories about gossip as a social bonding device (Gluckman 1963, 1968; Dunbar 1993, 1996, 2004). In line with expectations, participants in this study evaluated the behavior of the gossiping confederate slightly (though barely significant) more positive than the behavior of

Table 1 Mean scores (with standard deviation) on items measuring the perception of the confederate by condition

\begin{tabular}{|c|c|c|c|c|c|c|c|}
\hline Perception other player & & Control & Self-disclosure & Gossip & $F(2,57)$ & $p$ & $\eta_{p}^{2}$ \\
\hline \multirow[t]{2}{*}{ How friendly was the other player? } & $M$ & 4.84 & 5.55 & 5.79 & 3.08 & .05 & 0.101 \\
\hline & $S D$ & 1.07 & 1.50 & 1.03 & & & \\
\hline \multirow[t]{2}{*}{ How likeable was the other player? } & $M$ & 5.16 & 5.30 & 5.47 & 0.38 & .69 & 0.014 \\
\hline & $S D$ & 1.12 & 1.30 & .90 & & & \\
\hline \multirow[t]{2}{*}{ How much did you like the other player? } & $M$ & 4.45 & 4.55 & 5.15 & 2.14 & .13 & 0.072 \\
\hline & $S D$ & .83 & 1.64 & .81 & & & \\
\hline \multirow[t]{2}{*}{ How trustworthy was the other player? } & $M$ & 4.16 & 3.55 & 4.68 & $3.21 *$ & .04 & 0.105 \\
\hline & $S D$ & 1.12 & 1.70 & 1.29 & & & \\
\hline \multirow[t]{2}{*}{ How honest was the other player? } & $M$ & 4.37 & 4.55 & 5.37 & 2.41 & .10 & 0.080 \\
\hline & $S D$ & .76 & 1.79 & 1.71 & & & \\
\hline \multirow[t]{2}{*}{ How intelligent would you rate the other player? } & $M$ & 4.84 & 4.75 & 5.16 & 1.04 & .36 & 0.036 \\
\hline & $S D$ & .69 & 1.16 & .83 & & & \\
\hline \multirow[t]{2}{*}{ How cooperative was the other player? } & $M$ & 4.95 & 4.90 & 5.26 & 0.48 & .62 & 0.017 \\
\hline & $S D$ & 1.27 & 1.29 & 1.19 & & & \\
\hline \multirow[t]{2}{*}{ How much did you identify with the other player? } & $M$ & 3.16 & 3.60 & 3.95 & 1.74 & .19 & 0.059 \\
\hline & $S D$ & 1.34 & 1.54 & .97 & & & \\
\hline
\end{tabular}

$* p<.05$ ANOVA analysis for difference among the three conditions 
confederates in the other conditions. The gossiper was rated as more trustworthy, and there was a trend to rate her as being more friendly and perhaps more honest. In contrast to these findings, however, our participants were significantly, and clearly, less likely to cooperate with the gossiper in the PDG. Thus, there appears to be some mismatch between perception and actual behavior that requires further investigation.

Our results are somewhat congruent with Bosson et al.'s (2006) and Weaver and Bosson's (2011) work on how sharing negative news positively influences initial interactions between strangers. Our results are, however, not as strong and clear as the results from these prior studies. Weaver and Bosson (2011) used a procedure where the participants learned about an explicitly shared attitude expressing either like or dislike of a professor. While still a first impression, the shared information in that study was based on the participants' formed perceptions of a target that they both knew before the study started. In our experiment, the third party (the experimenter) is also a complete stranger to the participants; it is a person the participants have no experience with at all prior to coming to the experiment. In Bosson's studies, strangers found common ground in sharing negative attitudes but also in mutually knowing a third person. It may thus very well be, as others have suggested, that gossip does not really create social bonds as much as it reinforces social bonds (e.g., Ayim 1994; Bergmann 1993; Gelles 1989; Morreall 1994; Nevo and Nevo 1993; Smith, et al. 1999; Young 2001). Having a mutual acquaintance may be sufficient to start something, and adding a shared negative attitude towards this person can create social cohesion among strangers (Bosson et al. 2006; Weaver and Bosson 2011). Yet, having no mutual acquaintance and sharing negative gossip about a third person apparently has less of an effect. This result is an interesting finding that should be examined in more detail. We also propose that it should be extended to include third parties unrelated to the context wherein the gossipers interact, for reasons we outline below.

We advise future researchers to be mindful of the kind of gossip they use in their research. The gossip used in this experiment actually differed from the gossip used in the studies by Bosson and colleagues. To explain this, we refer to the work of De Backer et al. (2007), who distinguish between gossip information that is focused on the behavior (called strategy learning gossip) vs. gossip information that is focused on the person (called reputation gossip). Strategy learning gossip can be about anyone, whereas reputation gossip is about people we know, directly or indirectly. Strategy learning gossip is about what happened, from which the gossipers vicariously learn about successful behavior, appropriate behavior, and cultural norms. Reputation gossip is focused on the target, who is gossiped about, and alters the reputation of that person. In the studies of Bosson and colleagues, reputation gossip was used; it was all about shared or non-shared attitudes towards the target. In this study, the gossip story was a mix of both reputation gossip (who is not to be trusted: the experimenter) and strategy learning gossip (what happened: some people hit and run, and the gossiper finds this morally wrong). In this study, we are only certain about a shared attitude with regards to strategy learning gossip. The confederate merely expressed her dislike of a specific action. At the very end of the study, participants were also asked to rate the behavior of the target, and this revealed a matching negative score. The confederate and participants thus shared their attitudes towards the behavior gossiped about (strategy learning gossip). However, we do not know if any effect of reputation gossip was at play, because it could very well be the case that even though they rate this behavior as clearly negative, their overall impression of the target may not have been that negative. Indeed, perhaps a clearly shared dislike of attitudes (reputation information) is needed to establish closeness via gossip. That is, it may be that reputation gossip can start social cohesion among strangers, whereas strategy learning gossip is less suitable for social bonding purposes. We advise future researchers to investigate the influence of pure reputational gossip, such as the attitudinal information used in the studies by Bosson and colleagues, and pure strategy learning gossip, where the identity of the target remains completely unknown (e.g., mass media gossip dealing with what miraculously happened to your unknown people, see Davis and McLeod 2003).

Next, the timing in this experiment may have influenced how people responded to the gossip. Hearing the negative gossip about the target was not the very first information they received about the experimenter. All participants had briefly met the experimenter in the moment prior to the gossip exchange and may have already developed an attitude towards this person. If that very first impression was rated positively, and the participants thus formed an overall positive first impression about the experimenter, hearing negative information about this person from the confederate may have even elicited a disliking towards the confederate rather than towards the target to achieve psychological balance (see Heider 1958). The results from how participants rate the gossiper reveal that, on average, they do like her. Another form of imbalance may have been at play, however. That is, in the gossip condition, the confederate reveals that she observed the experimenter from her room, which may prime a certain level of proximity between the confederate and the experimenter. If this was the case, than the "us vs. them" may not have translated in the anticipated "gossipers vs. target" but in "the participant vs. the confederate/experimenter."

The most unexpected result from this study, however, is that participants cooperated significantly less in the gossip condition, despite the fact that they slightly trust and like the confederate most in this condition. An explanation for why a mismatch occurs between how the participants feel about the gossiper and what their behavior towards this person reveals is that attitudes alone cannot predict behavior. As the Theory of 
Planned Behavior (Ajzen 1991) outlines, control beliefs and perceived behavioral control are important predictors of behavior, next to normative beliefs and attitudes. That is, while participants may have liked the gossiper, a sense of lacking control over the situation may have distorted the process, resulting in negative behavior. The fact that the third party in our gossip story was the experimenter may have created a situation where the participants felt a lack of control or even distrust. Moreover, a perceived sense of distrust may have caused the participants to be more risk averse, which in the PD game usually means defecting (Kahneman and Tversky 1979). This possibility could explain how the participants in the gossip condition played in the first round of the game. For this reason, we advise future researchers who want to study the general effect of gossip on social cohesion and cooperation to use targets unrelated to the experiment. All measures regarding perceptions of the confederate in this study were taken after playing the PDG, so that these could not influence how people play the games. However, we did ask all participants about the behavior of the gossiper, target, and self-disclosing person of the hit-and-run stories used in the gossip and selfdisclosing condition. It may have been better to only ask participants, so as to not to raise any unnecessary suspicion during the entire experiment.

This study did also not control for individual differences that may partly explain the found results. The pattern of average to high trust and low cooperation is typical of a Machiavellian profile (see Gunnthorsdottir et al. 2002). And, it has also been shown that egoists and altruists respond differently to reputational incentives (Simpson and Willer 2008). These individual differences have not been taken into account in this study, and we suggest future research control for these differences when further investigating if and how gossip influences cooperation.

Next to individual differences, more work needs to be explored in terms of sex differences. We argued that gossip may influence cooperation differently in men and women, because of sex differences in cooperation (e.g., see Balliet et al. 2011), sex differences in social bonding (e.g., Young and Carter 2007), and sex differences in gossip (e.g., Hess and Hagen 2006a, b) and that it is therefore sensible to examine its effect at the within-sex level. We opted to conduct this experiment among women only, because it has been argued that women more than men use gossip (McAndrew 2014) for social comparison and bonding (e.g., Hess and Hagen 2006a, b; Leaper and Holliday 1995). The question is still open as to whether these results differ among male-male interactions and mixed dyads. To say that women more than men use gossip to establish and maintain social bonds of course does not mean that gossip may not establish similar effects in a male population. On the contrary, Dunbar's (1993) theoretical work on the social bonding function of gossip made no mention of anticipated sex differences. As we also outlined, men, more than women, tend to use gossip as a source of information, which may also positively influence the quality of the relationship with the person with whom they gossiped (Watson 2012). It must be noted, however, that levels of cooperation tend to be higher in male-male interactions compared to female-female interactions (Balliet et al. 2011), so that it may be harder to increase levels of cooperation in male-male dyads. If mixedsex dyads are to be used in future research, it must also be taken into account that women will become more cooperative and men will become less cooperative in a context where mating motives are more salient (Balliet et al. 2011). Further, this mixed-dyad mating salient context may elicit different motives to use gossip, leaning more towards the derogation of competitors (see Buss and Dedden 1990) than to the use of gossip as a social bonding mechanism.

Finally, in this study we tested the effect of negative gossip. However, it is having a good reputation that leads to the selective benefits and may explain why these people act generously (Hardy and Van Vugt 2006). The potential to gain reputational benefits drives prosocial behavior (Willer et al. 2010). It is known that people alter reputations by means of gossip by both slandering rivals and foes and boosting the reputation of family, friends, and allies (McAndrew and Milenkovic 2002). It may be worthwhile to investigate the impact of positive gossip on levels of cooperation among gossipers as well.

In conclusion, using levels of cooperation as a tool to measure social bonding, we used a social dilemma game to test whether gossip leads to more cooperative behavior among unknown gossipers. It was already established that strangers can connect when they express a shared dislike towards a mutually known third party (Bosson et al. 2006; Weaver and Bosson 2011). This study adds to that evidence by showing that merely sharing negative gossip information about another stranger may even positively influence first interactions between strangers. However, the results presented here further suggest that more is needed to bolster social cohesion and especially cooperation. In sum, gossip may start a positive first impression, but it remains unclear if it can truly create social cohesion, especially when gossip can decrease levels of cooperation.

\section{References}

Ajzen, I. (1991). The theory of planned behavior. Organizational Behavior and Human Decision Processes, 50(2), 179-211.

Arno, A. (1980). Fijian gossip as adjudication: a communicative model of informal social control. Journal of Anthropological Research, 36, 343-360.

Ayim, M. (1994). Knowledge through the grapevine: gossip as inquiry. In R. F. Goodman \& A. Ben-Ze'ev (Eds.), Good gossip (pp. 85-99). Lawrence: The University Press of Kansas. 
Balliet, D., Mulder, L. B., \& Van Lange, P. A. (2011). Reward, punishment, and cooperation: a meta-analysis. Psychological bulletin, 137(4), 594-615.

Baumeister, R. F., Zhang, L., \& Vohs, K. D. (2004). Gossip as cultural learning. Review of General Psychology, 8(2), 111-121.

Baxter, L. A., Dun, T., \& Sahlstein, E. (2001). Rules for relating communicated among social network members. Journal of Social and Personal Relationships, 18, 173-199.

Beersma, B., \& Van Kleef, G. A. (2011). How the grapevine keeps you in line: gossip increases contributions to the group. Social Psychological and Personality Science, 2(6), 642-649.

Beersma, B., \& Van Kleef, G. A. (2012). Why people gossip: an empirical analysis of social motives, antecedents, and consequences. Journal of Applied Social Psychology, 42(11), 2640-2670.

Bergmann, J. R. (1993). Discreet indiscretions: the social organisation of gossip. New York: Aldine de Gruyter.

Bohnet, I., \& Frey, B. S. (1999). The sound of silence in prisoner's dilemma and dictator games. Journal of Economic Behavior \& Organization, 38, 43-57.

Bosson, J. K., Johnson, A. B., Niederhoffer, K., \& Swann, W. B. (2006). Interpersonal chemistry through negativity: bonding by sharing negative attitudes about others. Personal Relationships, 13, 135-150.

Brown, D. E. (2004). Human universals, human nature \& human culture. Daedalus, 133(4), 47-54.

Buss, D. M., \& Dedden, L. A. (1990). Derogation of competitors. Journal of Social and Personal Relationships, 7(3), 395-422.

Cox, B. A. (1970). What is Hopi gossip about? Information management and Hopi factions. Man, 5(1), 88-98.

Davis, H., \& McLeod, S. L. (2003). Why humans value sensational news: an evolutionary perspective. Evolution and Human Behavior, 24(3), 208-216.

De Backer, C. J. S., Nelissen, M., Vyncke, P., Braeckman, J., \& McAndrew, F. T. (2007). Celebrities: from teachers to friends. Human Nature, 18(4), 334-354.

Dunbar, R. (1993). Coevolution of neocortex size, group size and language in humans. Behavioral and Brain Sciences, 16, 681-735.

Dunbar, R. (1996). Grooming, gossip and the evolution of language. London: Faber \& Faber.

Dunbar, R. (2004). Gossip in evolutionary perspective. Review of General Psychology, 8, 100-110.

Eder, D., \& Enke, J. L. (1991). The structure of gossip: opportunities and constraints on collective expression among adolescents. American Sociological Review, 56, 494-508.

Feinberg, M., Cheng, J. T., \& Willer, R. (2012a). Gossip as an effective and low-cost form of punishment. Behavioral and Brain Sciences, $35(1), 25-25$.

Feinberg, M., Willer, R., Stellar, J., \& Keltner, D. (2012b). The virtues of gossip: reputational information sharing as prosocial behavior. Journal of Personality and Social Psychology, 102, 1015-1030.

Feinberg, M., Willer, R., \& Schultz, M. (2014). Gossip and ostracism promote cooperation in groups. Psychological Science, 25(3), 656-664.

Foster, E. K. (2004). Research on gossip: taxonomy, methods, and future directions. Review of General Psychology, 8(2), 78-99.

Gelles, E. B. (1989). Gossip: an eighteenth-century case. Journal of Social History, 22, 667-683.

Gluckman, M. (1963). Gossip and scandal. Current Anthropology, 4, 307-315.

Gluckman, M. (1968). Psychological, sociological, and anthropological explanations of witchcraft and gossip: a clarification. Man, 3, 20-34.

Gunnthorsdottir, A., McCabe, K., \& Smith, V. (2002). Using the Machiavellianism instrument to predict trustworthiness in a bargaining game. Journal of Economic Psychology, 23(1), 49-66.

Hall, J. A. (2011). Sex differences in friendship expectations: a meta-analysis. Journal of Social and Personal Relationships, 28(6), 723-747.
Hannerz, U. (1967). Gossip, networks and culture in a Black American ghetto. Ethnos, 32, 35-60.

Hardy, C. L., \& Van Vugt, M. (2006). Nice guys finish first: the competitive altruism hypothesis. Personality and Social Psychology Bulletin, 32(10), 1402-1413.

Heider, F. (1958). The psychology of interpersonal relations. New York: Wiley.

Hess, N. H., \& Hagen, E. H. (2006a). Sex differences in indirect aggression: psychological evidence from young adults. Evolution and Human Behavior, 27, 231-245.

Hess, N. H., \& Hagen, E. H. (2006b). Psychological adaptations for assessing gossip believability. Human Nature, 17(3), 337-354.

Kahneman, D., \& Tversky, A. (1979). Prospect theory: an analysis of decision under risk. Econometrica, XLVII, 263-291.

Kurland, N. B., \& Pelled, L. H. (2000). Passing the word: toward a model of gossip and power in the workplace. Academy of Management Review, 25, 428-438.

Kuttler, A. F., Parker, J. G., \& La Greca, A. M. (2002). Developmental and gender differences in preadolescents' judgment of veracity of gossip. Merrill-Palmer Quarterly, 48(2), 105-132.

Leaper, C., \& Holliday, H. (1995). Gossip in same-gender and cross-gender friends' conversations. Personal Relationships, 2(3), 237-246.

Levin, J., \& Arluke, A. (1985). An exploratory analysis of sex differences in gossip. Sex Roles, 12, 281-286.

Levin, J., \& Kimmel, A. (1977). Gossip columns: media small talk. Journal of Communication, 27, 169-175.

Liang, M. (1993). Gossip: does it play a role in the socialization of nurses? IMAGE: Journal of Nursing Scholarship, 25, 37-43.

McAndrew, F. T. (2014). The "sword of a woman": gossip and female aggression. Aggression and Violent Behavior, 19, 196-199.

McAndrew, F., \& Milenkovic, M. (2002). Of tabloids and family secrets: the evolutionary psychology of gossip. Journal of Applied Social Psychology, 32(5), 1064-1082.

Merry, S. E. (1984). Rethinking gossip and scandal. In D. Black (Ed.), Toward a general theory of social control (Vol. 2, pp. 371-302). New York: Academic Press.

Morreall, J. (1994). Gossip and humor. In R. F. Goodman \& A. BenZe'ev (Eds.), Good gossip (pp. 56-64). Lawrence: The University Press of Kansas.

Nevo, O., \& Nevo, B. (1993). The tendency to gossip and its relation to vocational interests. Counselling Psychology Quarterly, 6(3), 229-238.

Nevo, O., Nevo, B., \& Derech-Zahavi, A. (1994). The tendency to gossip as a psychological disposition: constructing a measure and validating it. In R. F. Goodman \& A. Ben-Ze'Ev (Eds.), Good gossip (pp. 180-189). Lawrence: The University Press of Kansas.

Ortmann, A., \& Tichy, L. K. (1999). Gender differences in the laboratory: evidence from prisoner's dilemma games. Journal of Economic Behavior and Organization, 39(3), 327-339.

Paine, R. (1967). What is gossip about: an alternative hypothesis. Man, 2, 278-285.

Panchanathan, K., \& Boyd, R. (2003). A tale of two defectors: the importance of standing for evolution of indirect reciprocity. Journal of theoretical biology, 224(1), 115-126.

Percival, J. (2000). Gossip in sheltered housing: its cultural importance and social implications. Ageing and Society, 20, 303-325.

Piazza, J., \& Bering, J. M. (2008). Concerns about reputation via gossip promote generous allocations in an economic game. Evolution and Human Behavior, 29, 172-178.

Post, R. (1994). The legal regulation of gossip: backyard chatter and the mass media. In R. F. Goodman \& A. Ben-Ze'ev (Eds.), Good gossip (pp. 65-71). Lawrence: The University Press of Kansas.

Riegel, H. (1996). Soap operas and gossip. The Journal of Popular Culture, 29(4), 201-209. 
Rosnow, R. L. (1977). Gossip and marketplace psychology. Journal of Communication, 27(1), 158-163.

Sally, D. (1995). Conversation and cooperation in social dilemmas: a meta-analysis of experiments from 1958 to 1992. Rationality and Society, 7, 58-92.

Saunders, P. (1999). Gossip in an older women's support group: a linguistic analysis. In H. Hamilton (Ed.), Language and communication in old age: multidisciplinary perspectives (pp. 267-293). New York: Garland.

Schoeman, F. (1994). Gossip and privacy. In R. F. Goodman \& A. BenZe'ev (Eds.), Good gossip (pp. 72-84). Lawrence: The University Press of Kansas.

Simpson, B., \& Willer, R. (2008). Altruism and indirect reciprocity: the interaction of person and situation in prosocial behavior. Social Psychology Quarterly, 71(1), 37-52.

Smith, L. C., Lucas, K. J., \& Latkin, C. (1999). Rumor and gossip: social discourse on HIV and AIDS. Anthropology \& Medicine, $6(1), 121-131$.

Sommerfeld, R. D., Krambeck, H., Semmann, D., \& Milinski, M. (2007). Gossip as an alternative for direct observation in games of indirect reciprocity. Proceedings of the National Academy of Sciences, 104(44), 17435-17440.

Thomas, L. (1994). The logic of gossip. In R. F. Goodman \& A. BenZe-ev (Eds.), Good gossip (pp. 85-99). Lawrence: University Press of Kansas.
Watson, D. C. (2012). Gender differences in gossip and friendship. Sex Roles, 67(9-10), 494-502.

Weaver, J. R., \& Bosson, J. K. (2011). I feel like I know you: sharing negative attitudes of others promotes feelings of familiarity. Personality and Social Psychology Bulletin, 37, 481-491.

West, J. (1945). Plainsville, U.S.A.. New York: Columbia University Press.

Willer, R., Feinberg, M., Irwin, K., Schultz, M., \& Simpson, B. (2010). The trouble with invisible men. In Handbook of the Sociology of Morality (pp. 315-330). New York: Springer.

Wilson, D. S., Wilczynski, C., Wells, A., \& Weiser, L. (2000). Gossip and other aspects of language as group-level adaptations. In C. Heyes \& L. Huber (Eds.), The evolution of cognition (pp. 347-366). Cambridge: MIT Press.

Young, R. (2001). There is nothing idle about it: Deference and dominance in gossip as a function of role, personality, and social context. Unpublished $\mathrm{PhD}$ dissertation, Berkeley: University of California.

Young, L. J., \& Carter, C. S. (2007). Sex differences in affiliative behavior and social bonding. In J. B. Becker, K. J. Berkley, N. Geary, E. Hampson, J. P. Herman, \& E. A. Young (Eds.), Sex differences in the brain: from genes to behavior (pp. 139-152). New York: Oxford University Press. 